\title{
Using Ecological Footprints as a Policy Driver: the case of sustainable construction planning policy in London
}

\author{
Susan Moore \\ Cardiff School of City and Regional Planning \\ Cardiff University
}

Michael Nye

Centre for Environmental Risk

University of East Anglia

Yvonne Rydin

Bartlett School of Planning

University College London

Contact email: $\underline{\text { Y.Rydin@ucl.ac.uk }}$

\section{$\underline{\text { Abstract }}$}

The heuristic value of the ecological footprint $(\mathrm{EF})$ conceptual device has met with considerable political and civic buy-in at national, regional and local levels. It is seen as particularly valuable for visualising ecological overshoot but debates about methodological soundness have undermined this potential. This paper examines the emerging opportunities for advanced footprinting approaches which use input-output analysis to test 'what if' policy scenarios and hence turn EF into a proactive driver for 
sustainability-oriented policy development. It focuses on the London case and the specific arena of planning policy for sustainable construction.

\section{$\underline{\text { Acknowledgements }}$}

The work underpinning this paper was funded by HEFCE under its HEIF2 tranche.

The specific work using the REAP programme was also supported by the GLA. The authors wish to acknowledge the contribution of helpful discussions with policy

officers at the GLA and EF experts at SEI; however, the views expressed in this paper are those of the authors alone. 


\section{Using Ecological Footprints as a Policy Driver: the case of sustainable construction planning policy in London}

\section{Introduction}

The ecological footprint (EF) is widely advocated as a policy tool for visualising and analysing the environmental impact and ultimately unsustainable nature of our social and economic activities. EF has proved as popular at the local level as at national and global levels, as papers published in this journal demonstrate (Wackernagel, 1998; Barrett and Scott, 2003; Wood and Lenzen, 2003; Aall and Norland, 2005). However, there are debates about its value and the precise role that it can play in local policy for sustainability. In this paper, we consider the arguments for ecological footprinting as an awareness-raising tool and then move on to consider the role that it can play as a policy driver. We examine this by looking specifically at the context of London and the work of the Greater London Authority (GLA) in taking forward initiatives for sustainable construction. This example enables us to get beyond some of the simpler and narrower normative claims made for this policy tool to examine in detail how it can contribute to local sustainability policy development.

\section{Raising awareness of sustainability limits and the limits to awareness-raising} Conceptually simple, the EF is the area of land needed to support current lifestyles (production, consumption and waste assimilation) permanently given prevailing technologies. It is a quantitative assessment of the extent to which human use of ecological systems is exceeding bio-capacity. The key relationship is that between current human lifestyles and the extent of ecological carrying capacity 'overshoot'. Turning this around, an EF can also be used to assess how effective specific changes 
in resource-consuming and waste-producing activities can be in reducing the degree of 'overshoot'.

Two approaches to calculating EF have developed over time. The original compoundbased method devised by Wackernagel and Rees consists of aggregating the consumption of raw materials by accounting for the productive space of six major land types (fossil energy land, arable land, pasture, forest, built land and sea space) (cf. Barrett 2001; cf. Jorgenson 2003). This approach considers the human demand on each of these land types for a given population, no matter where that land may be geographically speaking. This method is considered by some to be inclusive and robust (Chambers et al. 2000). The primary unit of analysis is usually the nation state, wherein consumption is calculated in reference to trade flows and energy data.

The second, component-based method attempts to "retain the original philosophy behind footprinting" (Barrett, 2001, p.108), but it converts the human demand on the six major land types into activities which resonate with people's daily lives. Thus instead of considering the consumption of raw materials from the ecosphere, this approach considers the effect of transport, energy and water consumption and waste production. Where possible, data is collected for the specific area or activity under study and then converted into land equivalents. This method can, therefore, be applied to investigations that wish to measure the impact of different lifestyles, organisations, sub-national regions, products and services. Simmons et al. (2000) terms this a 'bottom-up' analytical approach to the derivation of footprint values. 
Proponents of EFs typically see them as a way to 'convince' political and economic leaders that "beyond reasonable doubt, the biophysical limits have been reached or exceeded" (Ferguson 1999, p. 153). Walker and Rees (1997) argue that the EF "begs policy relevant questions of just how large our ecological deficit is, and what must be done to reduce it?" (p. 100). The ability of the EF to deliver this message effectively is seen as one of its great attractions (Wackernagel, 1998; Barrett and Scott, 2003; Aall and Norland, 2005). Moffat suggests that:

If we are to actively engage in the process of making development sustainable we need to establish indicators so that we know if we are moving towards or away from a sustainable future. (Moffatt 2000, p. 361)

EFs are such an indicator. Even for sceptics such as van Kooten and Bulte (2000) the EF is a success with regard to raising awareness. Similary, Monfreda et al. (2004) argue, by tracking the core requirements for 'strong' sustainability and identifying the priority areas for 'weak' sustainability, EFs increase the likelihood of some degree of political action.

Some see a fundamental economic critique implicit in the EF and, therefore, consider its awareness-raising role to be potentially profoundly political. Rees (2003) sees EF as part of a paradigm shift from neo-classical to ecological economics, thereby redefining the 'environmental crisis' as a problem of 'human ecological dysfunction'. According to Rees, "[ $\mathrm{t}]$ his distinction is not a trivial one. The former term conceptually externalises the problem, effectively blaming it on a deficient environment that we then strive to 'fix'. By contrast, the latter term traces the problem to its source: humans, their behaviour and their institutions" (2003, p. 38). By using EF as an awareness-raising tool there is an implicit critique of neo-classical economic 
models of economy-environment relationships. Herendeen (2000, p. 357) further argues that the EF is a useful indicator of the indirect environmental effects of our dependence on imports and exports, and hence implies a critique of current trade relations.

This awareness-raising role has also been applied at the urban level. The 'city', in fact, played a primary role in the development of the EF concept. In Our Ecological Footprint (1996), Wackernagel and Rees presented a mental experiment to help readers conceptualise the implications of living beyond our biophysical limits, wherein they were asked to imagine a city enclosed in an expandable glass or plastic hemisphere that let in light but prevented material inputs or outputs. The authors asked: "how large would the hemisphere have to become before the city at its centre could sustain itself indefinitely and exclusively on the land and water ecosystems and the energy resources contained within the capsule?" (p. 10). Their original development of the EF was intended to conceptually and spatially redefine cities as urban ecosystems, crucially dependent on the life-support functions of natural ecosystems beyond their borders. Thinking about cities as ecosystems with an internal metabolism helps demonstrate that human enterprise, if left unchecked, could overtake the biophysical capacity of the ecosphere to support current (and even significantly reduced) human industrial metabolism, let alone our species' own biological metabolism (Rees 1997).

However the ability of the EF to be convincing in this role has been undermined by debates and critiques, focusing on its simplicity and methodology (summarised in Table 1). For those promoting the polemical function of EFs, simplicity can be seen as 
an advantage (Rees 2000, p. 373). Costanza located the 'power' of the EF in its aggregation and conversion of typically complex resource use patterns into a single number (2000, p. 342). But simplicity is also a major weakness cited by EF sceptics, who suggest that the conceptual tool oversimplifies the relationship between nature and society. For Van Kooten and Bulte, the EF may be a dangerous policy tool because the methods of aggregating data and other assumptions about substitutions can lead to false conclusions about local, regional and global sustainability: "wrongheaded policies could lead society down an unsustainable path where it was on a sustainable one previously" (2000, p. 388). Another aspect of this simplicity is, some argue, that the ecological footprint cannot take into account technological change or the adaptability of social systems: "The ecological footprint produces static estimates whereas nature and the economy are dynamic systems" (Rees 2000, p.373). Rees accepts that the EF is not a dynamic form of modelling, that it cannot make detailed forecasts and that prediction was never its intent.

[insert Table 1 about here]

Perhaps the methodological debates about EFs are more undermining of its polemical role. Such debate abounds in the literature. They tend to revolve around 'what gets counted', 'why or why not', and 'who says so' and concerns over data availability and quality. While the component-based method demonstrates considerable flexibility in its application, it is said to be more sensitive to variations in the data used.

Meanwhile, the component approach suffers from problems of data variability and reliability. Data on a life-cycle basis is a pre-requisite for the component footprint but, as Chambers et al. (2000) explain, this is often not available and proxy data and 
assumptions about activities and resource use are needed. But then, as Simmons et al. (2000) explain, complete information on material flows and energy usage, as required by the compound approach, is rarely available either. Compound analysis also often needs to rely on the application of proxy measures or indicators to represent variations in some aspects of regional or local consumption and the substitution of proxies can result in higher margins of error, thus in Simmons et al. 's (2000) opinion “offsetting one of the main benefits of the compound approach" (p. 378).

However, very few contributors to these methodological debates appreciate the implications of such controversies for the policy role of EF. While proponents of EF argue that it "forces the analysts both to explore critical issues and impacts that have been ignored to date and to declare their judgments and values in reflecting upon and deciding on the new trade offs revealed in making their policy and development decision" (Wackernagel and Rees 1996, p. 110), policy actors are reluctant to rely on a concept that can be so readily unpicked in terms of its basic methods and where there is not an accepted standard of calculation. Collectively such critiques have led to an air of scepticism amongst researchers and policy makers over the value or suitability of the EF as a sustainability tool. Van den Bergh and Verbruggen's (1999) commentary on the value of EF as a planning tool underscores this scepticism:

For any planning approach, a clear objective, constraints and instruments should be defined. This has not been done for the ecological footprint. ... In sum one cannot infer much on the basis of ecological footprints alone, neither what is the main problem nor what might be adequate policy solutions to the problem. (1999, p. 64) 
Lenzen et al. (2003) similarly comment that EF analysis has limited use as a policy and planning tool for indicating unsustainability because it does not reveal where the impacts really occur, what the nature and severity of these impacts are and how these impacts compare with the self-repair capability of the respective ecosystem. This has been supported by research into the value that local authorities place on EFs as a tool. A study of the policy and educational applications of the EF undertaken by SEI (see Barrett et al. 2004) found that of over 100 local authorities interviewed in UK and across Europe, most reported that it "was difficult to identify concrete policy outcomes as a result of the EF study" (p. 15). The political awareness that the EF tool enabled in these local contexts supported (as opposed to resulted in) the development of a range of environmental initiatives (e.g. fair trade policies, green procurement policies, green transport plans etc.).

This raises the question of how EF applications can be developed in a more fruitful direction. One significant attempt to overcome these problems of EF analysis involves developments based on input-output analysis. This builds on the potential of the component approach for exploring the impact of individuals' and organisations' decisions through scenarios by "manipulating and evaluating the various components" (Simmons et al. 2000, p. 379), but uses advanced input-output methods to take this further; (see Wood and Lenzen 2003 for a technical paper on using input-output analysis). This, according to Wiedmann et al. (2005) extends the potential for applications of the EF concept to inform scenarios, policies and strategies on sustainable consumption. The hope here is that such developments can resolve the data issues, establish a common standard for EF calculations and enable policy development, going beyond simple awareness raising. 
One example of this approach is the Resource and Energy Analysis Programme (REAP) developed by Stockholm Environment Institute in collaboration with the Centre for Urban and Regional Ecology at Manchester University and Cambridge Econometrics. REAP is a software package designed to provide all UK local authorities (among others) with a uniform methodology for material flow analysis and EF assessment initially using national statistics. Integrated resource-environment modelling lies at the core of REAP and this allows for policy scenarios to be developed and evaluated (SEI 2004, p. 2). The claim is that REAP allows local decision-makers to make day-to-day adjustments to the model based on preference changes or efficiency requirement changes and they can explore scenarios generated in relation to: population and demand technology and production; productivity and eco-efficiency; and environmental management. This entails the direct input by the user of parameters related to policy, markets, technology and consumption, in general.

On this basis, Barrett et al. (2004) argue that the EF is a tool that can be used to "inform policy makers on the impacts of the different policy options that they are considering and in turn can direct the derivation of a range of policy options leading towards the development of a comprehensive sustainable development strategy" (p.15). This takes it well beyond awareness-raising. To explore these claims and discuss the potential for EF to play a more proactive role in driving policy development, we examine a London case study, commenting on the application of a REAP analysis to drive the development of local planning policy on a specific policy issue (in this case sustainable construction). The next section outlines the current use 
of EF in the London context before going on to consider the value of a REAP analysis.

\section{London, ecological footprints and planning for sustainability}

London is an interesting case for considering the value of EF as a policy driver for a number of reasons. It is a major world city generating a considerable environmental burden, which it is worthwhile quantifying. The metro-level local authority for London - the Greater London Authority led by the elected Mayor for London under the scrutiny of the elected members of the London Assembly - has made sustainable development an overarching policy principle. While the story of establishing sustainable development principles for the GLA in the early days proved problematic (Rydin et al. 2004), there is no doubt that sustainability is now regarded as a significant policy objective within the authority. The London Plan (the spatial development strategy for the city) sets out a vision of a sustainable London, with detailed sustainable criteria in Policy 2A.1 (GLA 2005), supported by a number of environmental strategies - energy, air quality, biodiversity and waste - and there is reference to sustainable development in the other strategies, such as that for local economic development, as well.

Use has already been made of EF in London. Girardet's (1992) oft-quoted original calculation of the EF of London as an area 120 times the city's actual size set an early precedent for the use of the tool as a metaphorical device for illustrating the severity of urban ecological impact. Since then, a resource flow and EF analysis entitled City Limits has been undertaken by Best Foot Forward (BFF) for the GLA using the component-based method (BFF 2002). This concluded that the EF for London was 49 
global hectares, 293 its geographical area and 42 times its biocapacity. Each Londoner was analysed as consuming three times the average equal share of the Earth's productive resources. The same year that the City Limits report was published, the Mayor established a London Sustainable Development Commission (LSDC) as an independent source of advice on sustainability. Within a year the LSDC established a sustainable development framework of 13 principles organised around the themes of 'taking responsibility', 'developing respect', 'managing resources' and 'getting results' and sought to support the framework through the creation of a set of sustainability indicators. Following extensive consultation, London's EF was chosen as part of this indicator set under the 'managing resources' heading (LSDC, 2004). A revised version of the London EF is likely to be produced in the near future.

This has given rise to further consideration of whether the City Limits type of analysis is best suited to documenting the EF for London. GLA Economics commissioned a report to examine its value (2003). This concluded that EF could be a powerful tool if it could be shown to be both reliable and practical, but it was deemed to be neither. There were particular concerns over comparability over time, over treatment of the service sector and of the activities of London commuters. More recently, London First ${ }^{\mathrm{i}}$ and London Remade ${ }^{\mathrm{ii}}$ recalculated the EF of London largely using the compound-based approach (London Remade, 2005). This process endeavoured to identify specific practical steps that local government, residents, and businesses in particular could take to reduce the EF of the city and published reports identifying key 'impact areas' at three levels - the development site, the company, and an eco-site. Related work is being undertaken by Bioregional ${ }^{\mathrm{iii}}$ as part of its One Planet campaign, 
where individual communities are encouraged to reduce their EF from the current two to three planet's worth to one planet's worth.

In a context of four alternative EFs for the city, three quite recent, all calculated in different ways and oriented in slightly different directions with regard to policy, this raises the question of how this policy tool can influence policy development in London. We would argue that a more focused approach is needed if policy is to be assisted by the EF approach. This involves taking a more specific policy for analysis. The rest of this paper demonstrates this approach through consideration of London's planning policy for promoting sustainable construction and showing how a REAP analysis could evaluate this policy.

\section{Footprinting London's policy for promoting sustainable construction}

The promotion of sustainable construction patterns is a key policy objective of the Mayor and the GLA. This follows recognition of the environmental impact of construction, both as a production process in its own right and as creating the built context for all human activity with its consequent environmental impacts. The energy implications of construction and building design are particularly important. In 1999, Rees reported that buildings accounted for $40 \%$ of the materials and about a third of the energy consumed by the world economy (1999, p. 206). The House of Commons Environmental Audit Committee have looked at this in relation to housebuilding in the UK (HCEAC, 2005); looking at this sector alone, the Committee pointed to the prediction that carbon emissions from housing could constitute over 55\% of the UK's target in 2050 (p. 48). 
There is currently a range of national level initiatives in the UK promoting more sustainable construction including Best Practice guidance and labelling systems, such as the Building Research Establishment's (BRE) Environmental Assessment Method (BREEAM) and EcoHomes scheme, as well as national legislation such as the Sustainable and Secure Buildings Act 2004 and the enhancement of current building regulations. However, it is widely recognised that local planning policy has a role to play here. In their study of the barriers to the achieving sustainable construction in the housing sector, WWF-UK (2004) pointed to the lack of promotion of sustainable construction in planning policies and regulation as a key factor (alongside a lack of fiscal incentives and market barriers).

The London Plan (GLA, 2005) has taken up this challenge. In Policy 4A6, it sets out proposals for planners to demand high-level environmental standards in development proposals; these apply directly to strategic applications that the GLA determine and the aim is that the London boroughs councils (the lower tier of local government in London) will adopt similar policies for other schemes in their own plans. Additional guidance for London developers and planners has been provided in the form of the Sustainable Design and Construction Supplementary Planning Guidance, issued in draft form in 2005 with a final version a year later (GLA, $2005 \& 2006)$. This is particularly intended to help local authority planning departments implement Policy 4B.6 on sustainable construction. Extending to some 81 pages, the Supplementary Planning Guidance (SPG) covers issues such as: re-use of land and buildings, energy, material, and water; local natural systems; pollution, flooding, microclimate effects and recycling. A checklist for development control purposes is currently being developed by WWF-UK and the BRE to aid the implementation of the SPG at the 
borough level. On renewable energy, there is already specific guidance. With the initiative of the London Renewables Steering Group, an extensive renewable energy toolkit was developed to guide developers, planners and consultants on the incorporation of renewable energy infrastructure into developments (2004); the London Energy Partnership is now taking this work forward.

A REAP analysis can help interrogate the details of such a planning policy, identifying the likely overall impact and the appropriate prioritization of the different elements within it. Full details of such an analysis in relation to new housebuilding are provided in Nye and Rydin (2006). The methodology adopted was as follows. Stage One involved developing a benchmark scenario for the existing situation with regard to residential construction in London. Stage Two took the key policy documents emanating from the GLA to develop scenarios for the implementation of sustainable construction planning policy; in this case, the draft Supplementary Planning Guidance (the final version not having been issued at the time of analysis) was further defined through the development checklist being developed. The draft SPG set out standards for sustainable construction under a number of parameters (use of renewable energy, for example) and also includes a more stringent preferred standard, which the Mayor does not have the power to impose but would like to see achieved. Three scenarios were thus developed: a baseline and two possible futures arising from the implementation of the planning policy. REAP was then used to analyse and compare these scenarios (although the emphasis was on the best-case scenario of achieving preferred standards). 
The first point to make about such an analysis is that it does not generate the headlinegrabbing figures that would support effective awareness-raising among politicians or within society at large. Applying a REAP analysis to a full range of those standards in the GLA's draft SPG that could be evaluated using this tool, this suggests a best case savings of $0.5912 \mathrm{gh} / \mathrm{cap}$ against the baseline for new housebuilding over the London Plan period, amounting to $38 \%$. However this is not a $38 \%$ saving on the EF for London as a whole. Implementing sustainable construction measures will make only a limited contribution to reducing the total EF for London. This can also be deduced from analyses using 'older' EF methods. The City Limits analysis included construction materials within its materials and waste footprint and concluded that, at $27.8 \mathrm{~m}$ tonnes p.a., the construction sector consumed the most materials and produced the most waste (BBF 2002: 8). However, while construction materials accounted for $66 \%$ of tonnes consumed, it only represented $5 \%$ of the materials and waste footprint (p. 22). In a Swedish case, Haraldson et al. (2001) devised an EF (again using noninput-output measures) for the energy and materials required to construct a house. These elements were less than $5 \%$ of the total EF for the broader urban settlement, since household food and other energy consumption dominated the calculation.

Other REAP analyses also make this point. For example, in a study undertaken of the EF of Wales (WWF, 2005b) it was shown that more sustainable construction standards could produce a potential reduction of over $80 \%$ in the EF associated with new homes built in Wales but the overall effect on the Welsh EF would be less than a $2 \%$ reduction. In another example, a REAP analysis of the Thames Gateway development plans (WWF, 2003) showed that improving construction standards for the 200,000 new dwellings planned for this area to the east of London could result in 
a $32 \%$ reduction in $\mathrm{CO}_{2}$ emissions and $39 \%$ reduction in water use for 'Very Good' EcoHomes standards. If the standards were further pushed to the current best practice standard demonstrated in the south London BedZED development, there could be a $99 \%$ reduction in $\mathrm{CO}_{2}$ emissions and $65 \%$ reduction in water use. But again the related reductions in the total EF would be only $4 \%$ for the EcoHomes standard.

The value of applying an EF calculation in this way is that it demonstrates that change is possible through new planning policies and further that it allows a detailed examination of each element of a policy scenario to see how they contribute to the overall change in EF. It is through the disaggregation of the overall figure that more detailed guidance to policy makers can be achieved. For example, the REAP analysis of the impact of the draft SPG suggested that the largest savings would come from improving recycling rates in households through design features and improving the efficiency of energy systems in the dwellings, particularly if combined heat and power systems could be adopted. Thus a REAP analysis can show what the major priorities should be in seeking to influence new urban development. Another example of this fine-grained approach can be seen through the REAP analysis of other specific aspects of the draft SPG advice: the promotion of photovoltaic cells and the encouragement of passive solar design and the use of high mass building materials.

In relation to photovoltaic cells (PVCs), the draft SPG requires that developments not initialling incorporating PVCs should be able to support them if fitted at a later date. Studies of PVC use in climates similar to London suggest that $20 \%$ decrease in electric use is a likely outcome (Berger, 1997). Using REAP, the installation of PVCs in all houses built in London between 2005 and 2016 would produce a reduction in 
the EF associated with new build housing from 0.383 global hectares per capital (gh/cap) to $0.346 \mathrm{gh} / \mathrm{cap}$, or about $10 \%$. If the proportion of new houses so equipped falls, then obviously the reduction in EF also falls. For example, if only $10 \%$ of new houses are so fitted, then the fall in EF as a result is minimal, at only $0.004 \mathrm{gh} / \mathrm{cap}$. This emphasises the need to apply this policy extensively if it is to have any meaningful effect.

It is possible to compare this with other means of reducing energy consumption from the electric grid, such as pursuing passive solar design or high mass building materials. Here the analysis suggests that the use of high mass materials may actually marginally increase the EF due to the high embodied energy of such materials, while the pursuit of passive solar design could reduce the EF as against conventional new build by the relatively small amount of p.019 gh/cap (assuming a reduction of $15 \%$ in energy use as a result, an assumption derived following the results in the literature, interviews with building experts and a basic modelling exercise using DOE2). This suggests that installing PVCs should probably be a higher policy priority than passive solar design (although they may well be synergies individual cases) and that requiring high mass materials should be a policy pursued with caution. In this way an EF exercise can suggest specific and detailed questions for the development and application of policy.

This suggests that the role of EF as a policy driver in such cases is definitely not an awareness-raising role. Indeed such figures might lead policy actors and local communities to decide that the marginal impact on overall EF means that sustainable construction is not worth pursuing. This would be a mistake. Policy for sustainable 
development has to occur across a broad front. There are substantial environmental benefits from implementing sustainable construction methods. The use of aggregate EF figures can obscure this, but the use of more nuanced and detailed EF analyses as offered by input-output approaches can help refine policy in this area. It can suggest where the priority within sustainable construction policy should be placed.

There are some caveats that should be mentioned. EF is only a partial take on environmental sustainability; while it does consider water consumption it may not fully reflect the importance of local water security in the weighting that it gives this element within the calculation. It does not consider issues such as local biodiversity at all. And there are many aspects of the broader urban sustainability goal, particularly social aspects that are not within its remit. Furthermore the results of such an EF analysis are highly dependent on the specific assumptions. There would be much benefit in testing the results through sensitivity analysis, identifying the impact of different starting assumptions. Fortunately the interactive nature of new EF tools such as REAP allow such sensitivity analysis quite readily and this very exercise can contribute to the policy learning involved in integrating such a tool within ongoing policy development. The interactive nature of these tools should allay Costanza's fears that ignorance of where the numbers come from, how they are aggregated, as well as any uncertainties, weights, proxy measures and assumptions involved might be problematic for policy development, particularly for "busy" policy makers (2000, p.342). 


\section{Conclusion - getting beyond the metaphor}

Despite advances in the methodological and conceptual structuring of the EF approach, the early limitations of its framing still linger and hamper its widespread acceptance. Policy experience with the cruder forms of calculation and methodological disputes have undermined the value of EFs in terms of awareness raising, while it is difficult to find examples where the publication of an EF has actually resulted in changed policy direction. Yet there is considerable potential for input-output variants of EF analysis to provide detailed examination of the likely environmental mitigation associated with a specific policy measure.

This paper has sought to demonstrate this potential using the example of a single local policy issue, sustainable construction. It has showed how the 'snapshot' of London's current EF, together with projected scenarios for zero or low-energy development in the near future can be used to prioritise and develop policies which promote the construction best practices which are indeed the most sustainable for London. The prerequisites for such an approach can be summarised as follows:

- A completely specified policy with sufficient detail to be able to develop scenarios for the situation where the policy is implemented;

- The availability of data or, failing that, robust assumptions in order to draw up scenarios for the baseline situation and the situation associated with policy implementation; and

- The use of an interactive input-output tool with scope for sufficient disaggregation to match the different elements of the scenarios.

Given these conditions, it would be possible to calculate the change in EF resulting from the implementation of the policy. 
It may well be that the overall change may not be hugely significant. However, such a disaggregated approach still allows the relative importance of the different elements of the policy to be considered and thus priorities for policy implementation identified. This is the particular benefit of using EFs in this way to shape and develop policy. In developing this argument, we hope to have emphasised the need to look beyond the aggregate indicator of the $\mathrm{EF}$ as a visual metaphor lauded for its ability to raise public and political awareness of ecological overshoot. Rather we hope to have illustrated how a more nuanced application can aid detailed policy work, prioritising effort for sustainable development. In this way the EF can fulfil Barrett's hopes that - despite its inability to include every ecological system and human impact in its calculation - it nonetheless can provide a heuristic tool that builds on present knowledge and stimulates future-oriented thinking (Barrett 2001, p.117). 


\section{References}

Aall, C., and I.T. Norland (2005) 'The Use of the Ecological Footprint in Local

Politics and Administration: results and implications from Norway', Local

Environment, 10(2), pp.159-172.

Barrett, J. (2001). 'Component Ecological Footprint: Developing Sustainable

Scenarios', Impact Assessment and Project Appraisal, 19(2), pp. 107-118.

Barrett, J., R. Birch, N. Cherrett, and C. Simmons (2004) An Analysis of the Policy and Educational Applications of the Ecological Footprint, A Report to WWF Scotland (York, Stockholm Environment Institute).

Barrett, J., and A. Scott (2003) 'The Application of the Ecological Footprint: a case of passenger transport in Merseyside', Local Environment, 8(2), pp. 167-184.

Barrett, J., T. Wiedmann, and J. Ravetz. (2004) Development of Physical Accounts for the UK and Evaluating Policy Scenarios, REAP Report No. 1. (York, Stockholm Environment Institute).

Berger, W. (1997) 'The technical and behavioural potential for solar energy: a case study for the town of Lusk, Ireland' Renewable Energy, 13(1), pp. 55-66.

Best Foot Forward. (2002) City Limits: A Resource Flow and Ecological Footprint Analysis for Greater London (London, IWM). 
Chambers, N., C. Simmons, and M. Wackernagel. (2000) Sharing Nature's Interest:

Ecological Footprints as an indicator of sustainability (London, Earthscan).

Costanza, R. (2000) 'The Dynamics of the Ecological Footprint Concept', Ecological Economics, 32, pp. 341-345.

Ferguson, A. R. B. (1999) 'The Logical Foundations of Ecological Footprints', Environment, Development and Sustainability, 1, pp. 149-156.

Girardet, H. (1992) Gaia Atlas of Cities (London, Gaia Books).

Greater London Authority (GLA) (2005) The London Plan: The Mayor's spatial development strategy for Greater London (London: GLA).

GLA (2005) Sustainable Design and Construction: The Mayor's draft supplementary planning guidance (London, GLA).

GLA (2006) Sustainable Design and Construction: The Mayor's supplementary planning guidance (London, GLA).

GLA Economics (2003) London's Ecological Footprint: a review (London, GLA). 
Hansson, C. B. and M. Wackernagel. (1999) 'Rediscovering Place and Accounting Space: How to Re-embed the Human Economy'. Ecological Economics, 29(2), pp. 203-213.

Haradlsson, H.U., and U. Ranhagen (2001) 'Is Eco-living More Sustainable than Conventional Housing? Comparing sustainability preferences between two townships in Southern Sweden Journal of Environmental Planning and Management, 44(5), pp. 663-679.

Herendeen, R. A. (2000) 'Ecological Footprint is a Vivid Indicator of Indirect Effects', Ecological Economics 32, pp. 357-358.

HM Government (2005) Securing the Future: delivering UK sustainable development strategy, Secretary of State for Environment, Food and Rural Affairs.

House of Commons Environmental Audit Committee (2005) Housing: Building a Sustainable Future, First Report of Session 2004-05, Volume I. London, House of Commons Environmental Audit Committee.

Jorgenson, A. K. (2003) 'Consumption and Environmental Degradation: A CrossNational Analysis of the Ecological Footprint', Social Problems, 50(3), pp. 374-394.

Lenzen, M., S. Lundie, G. Bransgrove, L. Charet and F. Sack (2003) 'Assessing the Ecological Footprint of a Large Metropolitan Water Supplier: Lessons for Water 
Management and Planning Towards Sustainability', Journal of Environmental Planning and Management, 46(1), pp.113-141.

London Remade and London First (2005) Making London a Sustainable City:

Reducing London's Ecological Footprint. (London, London Remade and London First).

London Renewables and London Energy Partnership (2004) Integrating Renewable Energy into New Developments: Toolkit for planners, developers and consultants (London, GLA).

London Sustainable Development Commission (LSDC) (2004) 2004 Report on London's Quality of Life Indicators (London, GLA).

Moffatt, I. (2000) 'Ecological Footprints and Sustainable Development' Ecological Economics, 32, pp. 359-362.

Monfreda, C., M. Wackernagel, and D. Deumling.(2004) 'Establishing National Natural Capital Accounts Based on Detailed Ecological Footprint and Biological Capacity Assessment' Land Use Policy, 21, pp. 231-246.

North West Assembly with SEI and University of Manchester (2004) Footprint North West: a preliminary ecological footprint of the North West Region (Manchester, NW Assembly). 
Nye, M. and Y. Rydin (2006) Evaluating Sustainable Housing Construction Standards in London: Report to the GLA. The LSE SusCon Project, Centre for Environmental Policy and Governance. London, LSE.

Rees, W. E. (1997) 'Urban Ecosystems: The Human Dimension' Urban Ecosystems, 1, pp.63-75.

Rees, W.E. (1999) 'The Built Environment and the Ecosphere: a global perspective' Building Research and Information, 27(4/5), pp. 206-220.

Rees, W. E. (2000) 'Eco-Footprint Analysis: Merits and Brickbats' Ecological Economics, 32, pp. 371-374.

Rees, W. E. (2003) 'Economic Development and Environmental Protection: An Ecological Economics Perspective’ Environmental Monitoring and Assessment, 86(1), pp.29-45.

Rydin, Y, A. Thornley, K. Scanlon and K. West (2004) 'The Greater London Authority: a clash of organisational cultures' Government and Policy, 22, pp. 55-76

Simmons, C., K. Lewis, J. Barrett. (2000) 'Two Feet - Two Approaches: A Component-based Model of Ecological Footprinting' Ecological Economics, 32, pp. 375-380. 
van den Bergh, J. C. J. M. and H. Verbruggen (1999) 'Spatial Sustainability, Trade and Indicators: An Evaluation of the 'Ecological Footprint'" Ecological Economics, 29(1), pp.61-72.

van Kooten, G. C. and E. H. Bulte (2000) 'The Ecological Footprint: Useful Science or Politics?' Ecological Economics, 32, pp. 385-389.

van Vuuren, D. P. and E. M. W. Smeets (2000) 'Ecological Footprints of Benin, Bhutan, Costa Rica and the Netherlands' Ecological Economics, 34, pp. 115-130.

Wackernage, M. (1998) 'Footprints: recent steps and possible traps. The author's reply to Roger Levett's Response' Local Environment, 3(2), pp. 221-226.

Wackernagel, M. and W. Rees (1996) Our Ecological Footprint: Reducing Human Impact on the Earth (Gabriola Island, BC, New Society Publishers).

Wackernagel, M. and J. Silverstein (2000) 'Big Things First: Focusing on the Scale Imperative with the Ecological Footprint' Ecological Economics, 32, pp. 391-394.

Wackernagel, M. and J. D. Yount (2000) 'Footprints for Sustainability: The Next Steps’ Environment, Development and Sustainability, 2(1), pp.21-42.

Walker, L. A. and W. E. Rees (1997) 'Urban Density and Ecological Footprints - An Analysis of Canadian Households' in: M. Roseland (Ed.) Eco-City Dimensions: 
Healthy Communities, Healthy Planet. (Gabriola Island, BC, New Society Publishers).

Wiedmann, T., J. Minx, J. Barrett, and M. Wackernagel. (2005) 'Allocating ecological footprints to final consumption categories with input-output analysis' Ecological Economics.

Wood, R, and M. Lenzen (2003) ‘An Application of a Modified Ecological Footprint Method and Structural Path Analysis in a Comparative Institutional Study' Local Environment, 8(4), pp. 365-386.

World Wide Fund for Nature UK (WWF-UK) (2003) One Planet Living in the Thames Gateway (Surrey, WWF-UK).

WWF-UK (2004) One Million Sustainable Homes: moving best practice from the fringes to the mainstream of UK housing (Surrey, WWF-UK).

WWF-UK (2005a) Regional Footprints: solutions to reduce our global impact (Surrey, WWF-UK).

WWF-UK (2005b) Reducing Wales' Ecological Footprint: a resource accounting tool for sustainable consumption (Cardiff, WWF Cymru),

WSP Environmental Ltd. and Natural Strategies LLC (2003) Towards a Sustainable London: reducing the capital's ecological footprint Phase 1 Report: Determining 
London's Ecological Footprint and Priority Impact Areas for Action (London, London Remade/London First). 
Table 1 Summary of Current Debates on Ecological Footprints

\begin{tabular}{|l|l|}
\hline Strengths & Weaknesses \\
\hline Provides a single, aggregated index & $\begin{array}{l}\text { Results in a static measure that is only an } \\
\text { indicator of the current situation }\end{array}$ \\
\hline $\begin{array}{l}\text { Supports a visual metaphor that promotes } \\
\text { awareness }\end{array}$ & $\begin{array}{l}\text { Lacks common definitions and } \\
\text { assumptions with regard to data sources } \\
\text { and calculations }\end{array}$ \\
\hline $\begin{array}{l}\text { Measures human use of natural capital } \\
\text { and so demonstrates actual occurrence of } \\
\text { overshoot }\end{array}$ & $\begin{array}{l}\text { Disregards the potential for technological } \\
\text { improvements }\end{array}$ \\
\hline $\begin{array}{l}\text { Errs on the side of underestimating the } \\
\text { footprint size indicating the minimum } \\
\text { necessary conditions for ecological } \\
\text { sustainability }\end{array}$ & $\begin{array}{l}\text { Uses arbitrary spatial scales with no } \\
\text { intrinsic environmental meaning }\end{array}$ \\
\hline $\begin{array}{l}\text { Does not require specific knowledge of } \\
\text { each aspect of consumption and so can } \\
\text { capture indirect effects }\end{array}$ & $\begin{array}{l}\text { Relies on indirect weighting to translate } \\
\text { different ecological pressures into a } \\
\text { hypothetical area of land }\end{array}$ \\
\hline $\begin{array}{l}\text { Does not require knowledge of where } \\
\text { resources come from }\end{array}$ & $\begin{array}{l}\text { Does not distinguish between sustainable } \\
\text { and unsustainable land uses }\end{array}$ \\
\hline $\begin{array}{l}\text { Provides a tool for comparing ecological } \\
\text { burdens within and between populations }\end{array}$ & $\begin{array}{l}\text { Does not allow for trade-offs between } \\
\text { three ecological economics criteria: } \\
\text { efficiency, equity and sustainability }\end{array}$ \\
\hline $\begin{array}{l}\text { Addresses the ecological significance of } \\
\text { international and interregional trade }\end{array}$ & $\begin{array}{l}\text { Has an anti-trade bias that suggests } \\
\text { ecological autarky is desirable }\end{array}$ \\
\hline $\begin{array}{l}\text { Is consistent with the basic laws of } \\
\text { thermodynamics }\end{array}$ & $\begin{array}{l}\text { Does not address human well-being or } \\
\text { quality of life and thus only a partial } \\
\text { indicator of sustainable development }\end{array}$ \\
\hline
\end{tabular}

\footnotetext{
${ }^{\text {i }}$ London First is a business membership group supported by 300 of the capital's leading businesses with the stated shared objective of 'improving and promoting London.' http://www.london-first.co.uk

ii London Remade is a recycling programme aimed at increasing markets for recycled products and driving the development of an entrepreneurial recycling supply chain. The programme is based on a partnership between the business community, public and not-for-profit sectors. According to its website, London Remade "uses recycling as a vehicle to drive economic and social regeneration and is principally funded by the London Development Agency to deliver green procurement and business support programmes." http://www.londonremade.com

${ }^{\text {iii }}$ Bioregional is a charity with 6 spin-off companies, who campaign on a range of environmental issues and were partners in the pioneering BedZed development undertaken by the Peabody Trust. http://www.bioregional.com
} 